DOI: 10.12957/demetra.2016.22525

\title{
O corpo modelado e generificado como espelho da contemporaneidade: considerações a partir da teoria queer
}

\section{The modeled and gendered body as a mirror of contemporary society: considerations from the queer theory}

Manoel Antônio dos Santos'

Raquel de Freitas Banuth'

Érika Arantes de Oliveira-Cardoso'

1 Universidade de São Paulo, Departamento de Psicologia, Faculdade de Filosofia, Ciência e Letras de Ribeirão Preto. Ribeirão Preto-SP, Brasil.

Correspondência / Correspondence

Manoel Antônio dos Santos

E-mail:manoelmasantos@gmail.com

\section{Resumo}

O objetivo deste estudo teórico é tecer algumas reflexões sobre a relação entre comportamento alimentar e gênero na contemporaneidade. Consideramos que a teoria queer oferece uma vertente teórica profícua para responder a essa proposta. Nosso argumento central é que o comportamento alimentar e os cuidados em relação ao corpo são performances e também produtos e produtores de gênero. Consequentemente, são produtos e produtores da identidade do indivíduo. Após uma breve explanação de conceitos-chave da teoria queer, discutiremos a influência dos discursos sociais engendrados pela mídia, redes sociais e ciências da saúde nos corpos, pontuando seus efeitos sobre o sujeito. Ao mesmo tempo, demonstraremos que a exposição a essas práticas discursivas não tem uma relação direta de causa e efeito, sendo necessário considerar a transformação que esses discursos sofrem na apropriação que deles é feita em cada processo de subjetivação, o que produz maior ou menor capacidade de agenciamento individual no tecido social.

Palavras-chave: Gênero e Saúde. Comportamento Alimentar. Estilo de vida. Transição Nutricional. Estética.

\section{Abstract}

The aim of this theoretical study is to make some reflections on the relationship between eating behavior and gender in contemporary times. We believe that queer theory provides a useful theoretical model to develop this approach. Our central argument is that eating behavior and our body care are performances and also 
products and producers of gender. Consequently, they are products and producers of individual identity. After a brief explanation of key concepts of the queer theory, we discuss the influence of social discourse engendered by the media, social networks and health sciences on human bodies, highlighting its effects on the subject. At the same time, we demonstrate that the exposure to these discursive practices does not have a direct cause and effect relationship, hence one should consider the transformation that these discourses undergo when they are appropriated in each process of subjectivity, which produces greater or lesser capacity of individual agency in social life.

Key words: Gender and Health. Feeding Behavior. Lifestyle. Nutritional Transition. Esthetics.

\section{Introdução}

A teoria queer não constitui exatamente uma teoria, no sentido estrito da palavra, mas um movimento teórico contemporâneo que vem ganhando força no campo dos estudos de gênero. Os teóricos queer têm dedicado atenção especial à importância que o corpo assume na construção da subjetividade na era contemporânea.

Butler, ${ }^{1}$ filósofa de destaque nessa seara, afirma que a identidade de gênero é performativamente constituída. A autora contraria a tese bastante difundida de que gênero seja uma construção cultural sobre a biologia, ou um atributo que as pessoas possuem. Para Butler, o gênero é um fazer, uma performatividade que, ao mesmo tempo em que é resultante das normas de gênero vigentes, produz ela própria o gênero. ${ }^{1}$ Assim, assumindo essa perspectiva, o gênero é produzido e produz a si mesmo. Para Preciado, ${ }^{2}$ outro nome fundamental na tessitura dos estudos queer, o gênero se dá na materialidade dos corpos.

Podemos pensar que, sendo o gênero um fazer, comporta algo de abstrato, mas tem também algo de concreto, uma vez que não pode ser senão nos corpos. Desse modo, gênero é uma categoria relacional que acontece tanto no plano simbólico quanto material.

Butler afirma que os corpos são divididos sexualmente e só são compreendidos a partir do momento que o gênero lhes dá significado. "A identidade seria assegurada por conceitos estabilizadores de sexo, gênero e sexualidade"l e, desse modo, tudo o que disser respeito ao corpo, tudo o que for performado pelos indivíduos, será compreendido em termos de gênero e em termos identitários. 
A literatura mostra que a sociedade contemporânea é extremamente calcada na valorização das performances dos indivíduos por meio de seus corpos. Práticas alimentares, intervenções cirúrgicas com finalidade estética, tatuagens, piercings, escarificações e diversos outros recursos que resultam em alterações da aparência física são estratégias cada vez mais utilizadas em busca de um corpo idealizado.

O culto apolíneo ao corpo é reflexo da sociedade contemporânea. ${ }^{3}$ Depois da entronização desse ideal de formato corporal, uma profusão de serviços foi criada no campo da medicina, nutrição, educação física, estética e cosmetologia, instaurando uma implacável mercantilização do corpo. Essa indústria do "bem-estar físico" dissemina a ideia de que é possível comprar o corpo que se deseja em um mercado de ofertas diversificadas. Seguindo a lógica da oferta e procura em um mercado cada vez mais concorrido, inúmeras possibilidades de intervir no corpo são colocadas à disposição de quem tem poder aquisitivo suficiente para bancá-las. Essas intervenções são uma espécie de commodities do narcisismo contemporâneo colocadas à disposição dos indivíduos. Alvo e locus privilegiado das transformações, o corpo pode, assim, ser continuamente remodelado, reeducado, corrigido e aperfeiçoado, seguindo uma estética própria dos corpos passíveis de ser modificados. Surge o que os autores chamam de "desenho do corpo construído" pela via das cirurgias plásticas, das dietas milagrosas e da malhação frenética em academias, que prometem esculpir os corpos de acordo com os estereótipos corporais vigentes em nossa época. ${ }^{4}$

A alimentação é parte dessa estratégia composta por uma variedade de intervenções que são disponibilizadas na contemporaneidade para delinear o ideal de corpo enaltecido. É verdade que os hábitos alimentares seguem as normas de gênero estabelecidas ${ }^{5}$ e que estas são, como tais, fruto do tempo em que se vive, podendo ser reinventadas em cada período histórico. Também está sujeito a transformações aquilo que cada contexto social e quadra histórica elege como formato ideal do corpo.

Os ideais de forma e peso corporal variam enormemente ao longo da história, uma vez que os padrões estéticos consagrados são condicionados pelas características destacadas como apreciáveis em cada período. ${ }^{4} \mathrm{Em}$ outras palavras, a ostentação crescente de um corpo modelado, "sarado", emagrecido, tonificado, anabolizado, "bombado" e siliconado está intimamente associada à época e à sociedade em que vivemos e à hipervalorização da imagem em detrimento do conteúdo.

Partimos da noção de que o corpo altamente idealizado no modo de vida contemporâneo é um corpo generificado, ou seja, atravessado pela história e pelos imperativos normativos que são outorgados por sua condição/inserção gendrada. E indagamos: em que medida o fato de esse ideal de corpo ser inexequível para a maior parcela da população não contribui para os altos níveis de insatisfação corporal a que estamos expostos na atualidade, produzindo um terreno propício para a instalação de psicopatologias que têm, em suas raízes, as graves distorções da imagem corporal, 
como a anorexia nervosa e a bulimia, ou condições mórbidas ligadas à compulsão alimentar, como a obesidade, que vem adquirindo proporções alarmantes de pandemia ${ }^{6-8}$ na última década?

Considerando esses pressupostos, este estudo tem por objetivo tecer algumas reflexões sobre a relação entre comportamento alimentar e gênero na contemporaneidade. Pretendemos oferecer ao leitor aportes para reflexão sobre a relação entre os hábitos alimentares, os cuidados dispensados ao corpo e o gênero. Assim, almejamos refletir, a partir de uma perspectiva queer, sobre como corpo, alimentação e gênero se relacionam, produzindo subjetividades.

\section{Método}

Para alcançar o objetivo proposto, estabeleceremos um percurso teórico-reflexivo com fundamentação na literatura dedicada à temática investigada.

\section{Compreender a alimentação como processo generificado}

Em um olhar superficial, o corpo humano pertenceria aparentemente à natureza, uma vez que o funcionamento fisiológico é semelhante ao de muitos animais. De falto, há pontos de aproximação em seu metabolismo, fisiologia e ergonomia. No entanto, somando-se a essas dimensões, o corpo humano é resultado de relações sociais e apropriações culturais. ${ }^{9}$ Nessa medida, também constituem o corpo os discursos (adjetivos, elogios, valorização ou recusa de certas partes corporais) e saberes diversos que o atravessam, como a medicina, bioquímica, antropologia, psicologia, história, feminismo. ${ }^{9}$ Visto nessa perspectiva, o corpo é a resultante de vetores de força, produto engendrado por uma rede discursiva. Para Foucault, ${ }^{10}$ o corpo é o local prioritário de ação do poder e do controle social.

Margaret Mead, ${ }^{11}$ já em 1936, atentava para o modo diferencial, no interior de uma mesma cultura, como meninos e meninas são criados com o aporte de técnicas corporais distintas, o que resulta em diferenças no uso da força física, nas habilidades e em seus significados. Atentaremos a esse aspecto da experiência corporal. Daremos destaque à constatação de que o corpo também é generificado, ou seja, é tocado e forjado pela rede de processos inclusos nas dinâmicas de gênero. ${ }^{12}$

Se os corpos adquirem significado social a partir do gênero, e se o gênero se dá na materialidade dos corpos, ${ }^{2}$ tudo o que se faz para modificar os corpos, alterar sua funcionalidade, compensar suas limitações, cuidar da aparência física e velar suas supostas imperfeições é uma questão relacionada ao gênero. 
No modo de vida contemporâneo, investimos maciçamente em nossos corpos. Construímos os corpos de modo a adequá-los aos critérios estéticos, higiênicos e morais dos grupos a que pertencemos. Imposições de normas de saúde, vigor, vitalidade, juventude, beleza e força são significadas de formas diferentes nas diferentes culturas, e são também atribuídas de formas distintas aos corpos de homens ou de mulheres. Por meio de diferenciados processos, tais como cuidados físicos, exercícios, roupas, adereços, perfumes, cirurgias corretivas e dietas alimentares, inscrevemos em nossos corpos marcas de identidade e, consequentemente, de diferenciação. ${ }^{13}$ É interessante notar que o anseio de diferenciação, ligado aos processos de subjetivação disponíveis no mundo atual, caminha na contramarcha da tendência imperativa a padronização e uniformização de corpos e mentes, uma exigência do capitalismo na sua fase contemporânea e neoliberal, conhecida como globalização.

Os corpos sofrem influências distintas de acordo com o gênero que os rege. Sabe-se que a valorização do corpo feminino "perfeito" não é um fenômeno recente, ainda que o imperativo do corpo "perfeito" seja variável em relação à época, localidade e cultura. É recente a valorização de padrões estéticos extremamente magros e esguios como requisitos normativos para que um corpo seja considerado belo. Nesse contexto, o corpo tem um valor simbólico, representando uma senha para a plena aceitação e inserção social da mulher em uma sociedade estratificada por classes e hierarquizada por gênero, e a magreza vem sendo considerada um pré-requisito para que isso aconteça. ${ }^{14}$

As condições sociais precedem ao corpo e formam as condições em que este se desenvolve, ${ }^{6}$ ganhando visibilidade ou invisibilidade, flexibilidade ou enrijecimento, saúde ou morbidez. Assim, o corpo ultrapassa os limites estritos traçados pela sua natureza biológica e é reificado e generificado no plano das relações sociais, transformando-se em objeto e ferramenta de reconhecimento social. É exatamente para isso que ele é incessantemente construído, formatado, forjado e esculpido. ${ }^{15}$

O saldo do exaustivo exercício de cultuar o corpo perfeito é uma mudança da moralidade dominante: se na época vitoriana a moralidade tinha por objeto a regulação da sexualidade, atualmente se constitui em um discurso sobre a dieta. ${ }^{16} \mathrm{~A}$ moral da alimentação conserva as mesmas características da moral da sexualidade, manejando elementos básicos da condição humana, tais como a suscetibilidade à culpa, o pecado e a expiação. ${ }^{17}$ Freud foi um dos herdeiros diletos do conservadorismo vitoriano que, na esfera da intelectualidade, começou a refletir sobre a subjetividade em uma nova perspectiva. Mais de um século se passou desde o advento da psicanálise, e a pretendida ciência do desejo ainda almeja compreender o mal-estar contemporâneo. 


\section{O corpo é o marcador da identidade}

Nos processos de subjetivação contemporâneos, o corpo é a própria identidade do sujeito, e a aparência, o comportamento e a silhueta designam cada vez menos as origens sociais e cada vez mais a personalidade e as particularidades pessoais. ${ }^{15} \mathrm{O}$ gordo passa a ser percebido socialmente como indivíduo desleixado, negligente e incapaz de cuidar de si mesmo, já que se recusa a mudar seus hábitos perniciosos. ${ }^{7-8}$ De fato, a hipervalorização estética sugere que o corpo é perfeitamente adaptável por meio da deliberação firme da vontade pessoal, passando a mensagem moralizadora de que o sujeito pode ter o corpo que deseja, bastando acionar os recursos disponíveis, como o conhecimento adquirido sobre os efeitos da alimentação combinados com exercícios físicos bem planejados. ${ }^{18}$

Nesse contexto sociocultural, ganhou força a ideia de que é preciso levar o indivíduo contemporâneo a uma progressiva conscientização de que seus hábitos alimentares são um dos principais determinantes de sua saúde, criando-se a mentalidade de que a prevenção de condições crônicas está nas mãos de cada um e que basta querer ("ter força de vontade") para se assegurar uma vida longa e de qualidade. O slogan "você é o que você come" é a mais perfeita tradução desse pensamento maniqueísta, que no fundo endossa a crença de que a alimentação designa também a essência do sujeito, ou seja, define a sua identidade.

Não há dúvidas de que a alimentação é uma responsabilidade individual e uma questão social e coletiva, além de ser um fator de boa saúde. Questão social porque é traçada uma relação complexa entre a comida e todas as regras e códigos culturais construídos para o ato de comer. Na questão da responsabilidade individual está embutida a noção de que aquilo que as pessoas comem torna-se parte delas pela incorporação, uma vez que algo do exterior que é colocado no seu interior passa a ser parte do corpo do sujeito, pois dá forma ao corpo. ${ }^{16}$

A chamada "alimentação saudável" pode ser entendida como uma instituição política e social, que clama por ser uma forma de promoção de saúde e prevenção da obesidade, entre outras condições crônicas de saúde. É um conceito que tem mudado desde o início da modernidade, partindo de uma preocupação com as deficiências nutricionais e o flagelo da fome até chegar aos temores do consumo excessivo de nutrientes e calorias, o que está atrelado também à realidade econômica do país, que vem buscando o fortalecimento da economia, o avanço da agricultura e a redução da faixa de pobreza. O conceito de alimentação saudável se preocupa não apenas com os aspectos biológicos do indivíduo, mas também com a relação adequada do padrão de consumo alimentar com a natureza e as características sociais: consumismo, imediatismo, individualismo, preocupação com a aparência, a beleza e o culto ao corpo..$^{15}$

É interessante olharmos para essa questão em uma perspectiva histórica. Aperfeiçoar o corpo para atingir a perfeição ou aproximar-se ao máximo das regras de beleza vigentes na era 
contemporânea, como manter-se eternamente jovem e magra, tornou-se o ideal feminino da atualidade. ${ }^{14}$ No final do século XX e início do século XXI, o culto ao corpo virou uma obsessão, uma autêntica corpolatria, pelo menos entre as mulheres urbanas de camadas médias. Nesse período, as modelos adquiriram status de celebridade e passaram a ser uma carreira desejada pelas adolescentes e jovens brasileiras, iludidas com as supostas benesses de se tornarem clones de top models, como a brasileira Gisele Bündchen, ícone das passarelas mundiais. Assim, com os olhares hipnotizados pela miragem do corpo escultural, a combinação entre corpo e prestígio se tornou um elemento fundamental da cultura brasileira. ${ }^{19}$

Os avanços tecnológicos, especialmente no campo da biomedicina, são uma notável ferramenta para modificação do corpo. Hoje a engenhosidade humana é capaz de operar grandes transformações sobre a natureza que determina o desenho do corpo, antes vista como um limite intransponível. Cremes, loções, pílulas, dietas, injeções, recursos anunciados como panaceias universais, ao lado de aparelhos que reduzem medidas, medicamentos miraculosos e cirurgias plásticas rejuvenescedoras são recursos dos quais se pode lançar mão para modificar quase instantaneamente a arquitetura do corpo, flexibilizando-o ou endurecendo-o, o que tem reduzido cada vez mais o intervalo entre o corpo sonhado e o corpo possível. Nesse caldo cultural, o corpo assume um caráter de plasticidade quase infinita, ${ }^{14}$ na medida em que pode se amoldar com grande facilidade aos caprichos humanos, atendendo também ao imperativo do delírio mefistofélico da imortalidade.

A indústria cultural ensina às mulheres que cuidar do corpo é o caminho que conduzirá à felicidade individual, ${ }^{14}$ um ensinamento que pode causar frustração na maioria das pessoas, visto que o corpo considerado belo está reservado principalmente, e com mais facilidade, a quem possui capital financeiro suficiente para modelá-lo. Em outros termos, o corpo idealizado é um corpo para poucos, embora a publicidade venda a ideia de que é acessível a todos, desde que se esforcem. Portanto, um corpo desejado por todos, mas acessível para poucos.

A mídia é de fato uma importante ferramenta de veiculação de padrões de beleza e da associação desses padrões à ideia de sucesso e felicidade. No entanto, não se pode descartar a agência das pessoas frente a esses estímulos e aos apelos sedutores recebidos da mídia. Se a televisão, o cinema, a propaganda e as mídias sociais veiculam determinado conteúdo, há que se estar atento não apenas ao que é disseminado por esses meios, mas também à reação das pessoas frente a isso e à maneira como elas agem diante deles. Assim, escapamos de cair no perigoso discurso que concebe a mídia como essencialmente manipuladora e as pessoas como receptáculos passivos dos conteúdos aos quais estão expostas diariamente.

Concordamos com Connell \& Pearse, ${ }^{12}$ quando sustentam que não se deve exagerar na consideração da docilidade dos corpos. As autoras afirmam que os corpos participam de regimes disciplinares, como o da mídia, não porque são dóceis, mas porque são ativos e buscam prazer, 
experiência e transformação. As autoras dão o exemplo do uso do salto agulha - nos apropriaremos dessa analogia para nos referirmos a dietas ("regimes de emagrecimento").

Ninguém obriga as mulheres a submeterem a regimes ou outros procedimentos estéticos para atingirem seus ideais de magreza e prolongamento da juventude. Restrições alimentares por vezes são processos difíceis e sofridos, mas também são prazerosos porque trazem benefícios. ${ }^{12}$ Cabe aos profissionais de saúde investigarem que tipo de prazer é obtido e o que isso vem acarretando na vida da pessoa. Um exemplo é que indivíduos que colocam para si metas e dietas impossíveis de cumprir podem, na verdade, estar criando o contexto para uma possibilidade de transgressão de seu processo de reeducação alimentar, na busca de maximização de um prazer que será muito intenso quando for finalmente alcançado por meio do ato transgressor. ${ }^{20}$

Devemos ter em mente que os corpos não são apenas objetos do processo social, mas também atuam como participantes ativos do processo social, ${ }^{12} \mathrm{o}$ que abre uma brecha para que possamos usar a capacidade de agência dos corpos a favor de sua saúde e bem-estar. Faz-se necessário considerar que o comportamento alimentar performatizado pode ser hostil ao bem-estar físico, e investigar que variantes pessoais e sociais estariam por trás dessa performance.

Dito isso, desejamos apontar que um caso extremo de como a cultura constrói o corpo de seus membros são as patologias somáticas e psíquicas que essa construção provoca. Cada sociedade produz suas próprias patologias e psicopatologias, como a histeria na época vitoriana e a depressão na contemporaneidade. No tempo de Freud, a histeria, que resultava em mulheres cegas, paralíticas, emocionalmente instáveis e que desmaiavam com facilidade, evidenciava uma situação insuportável de subordinação às normas de gênero por parte das mulheres. A anorexia e a bulimia, transtornos alimentares que põem a vida em risco, podem ser interpretados como a expressão física da coerção social sobre o corpo feminino, comumente sujeito a padrões idealizados. ${ }^{16}$

\section{Considerações finais}

Os hábitos alimentares, além de serem constructo sócio-histórico, são processos generificados. O cuidado ao corpo é uma performance que, estando relacionada ao gênero, atinge homens e mulheres de maneiras diferenciadas. Meios de comunicação e redes sociais são instrumentos que influenciam nos padrões socialmente valorizados de beleza e no cuidado ao corpo, mas não se pode ignorar a participação ativa do indivíduo na interpretação e prática das informações que recebe. O sujeito é capaz de receber a informação, digeri-la, transformá-la e agir de acordo com sua individualidade, em uma relação complexa entre condições culturais e aspectos subjetivos, cultura de consumo e hábitos alimentares. 
Ao considerarmos as práticas de emagrecimento como práticas relacionadas ao gênero, faz-se necessário considerar que, uma vez que as performances de gênero envolvem corpos, o comportamento performatizado pode ser hostil ao bem-estar físico. Assim, em uma intervenção dirigida à modificação dos padrões alimentares, há que se considerar que está se tocando na interseção entre diversos fatores, tais como padrões de gênero, contexto sociocultural e aspectos subjetivos.

\section{Agradecimentos}

Ao Conselho Nacional de Desenvolvimento Científico e Tecnológico - CNPq, pela bolsa de Produtividade em Pesquisa Nível 1B concedida ao primeiro autor, e pela bolsa de Iniciação Científica (PIBIC-USP) concedida à segunda autora.

\section{Referências}

1. Butler J. Problemas de gênero: feminismo e subversão da identidade. Rio de Janeiro: Civilização Brasileira; 2015.

2. Preciado B. Manifesto contrassexual. São Paulo: N-1 Edições; 2014.

3. Castro AL. Culto ao corpo e sociedade: mídia, estilos de vida e cultura de consumo. São Paulo: Annablume; Fapesp; 2003.

4. Santos MA, Garcia RWD, Liotino-Santos M. A sujeição aos padrões corporais culturalmente construídos em mulheres de baixa renda. Demetra 2015; 10(4);761-774.

5. Silva LAS. O corpo, o comer e a comida: um estudo sobre as práticas corporais e alimentares no mundo contemporâneo. História: Questões \& Debates 2011; 54:287-290.

6. World Health Organization. Obesity and overweight. Factsheet. Genebra: WHO; 2015. Disponível em: http://www.who.int/mediacentre/factsheets/fs311/en/

7. Mattos RS, Luz MT. Sobrevivendo ao estigma da gordura: um estudo socioantropológico sobre obesidade. Physis 2009; 19(2):489-507.

8. Neves AS, Mendonça ALO. Alterações na identidade social do obeso: do estigma ao fatpride. Demetra 2014; 9(3):619-63.

9. Gastaldo EL, Braga AA. Corporeidade, esporte e identidade masculina. Revista Estudos Feministas 2011; 19(3):875-893.

10. Foucault M. Vigiar e punir. Petrópolis: Vozes; 1980.

11. Mead M. Sexo e temperamento. 3 ed. São Paulo: Perspectiva; 1988.

12. Connell R, Pearse R. Gênero: uma perspectiva global. São Paulo: nVersos; 2015. 
13. Louro GL. Pedagogias da sexualidade. In: Louro GL, Weeks J, Britzman D, Hooks B, Parker R, Butler J, editores. O corpo educado. Belo Horizonte: Autêntica; 2000. p. 7-34.

14. Zorzan FS, Chagas ATS. Espelho, espelho meu, existe alguém mais bela do que eu? Uma reflexão sobre o valor do corpo na atualidade e a construção da subjetividade feminina. Barbarói 2011; 34:161-187.

15. Formiga SC. O design do corpo como determinante da identidade feminina. II Seminário Internacional de Educação Intercultural, Gênero e Movimentos Sociais; 2003; Florianópolis, SC.

16. Lazzarini ER, Batista CF, Viana TC. Transtornos alimentares, o corpo e a clínica psicanalítica contemporânea. In: Viana TC, Leal I, organizadores. Sintomas alimentares, cultura, corpo e obesidade: questões clínicas e de avaliação. Lisboa: Placebo; 2013. p. 73-91.

17. Herrmann F, Minerbo M. Creme e castigo: sobre a migração dos valores morais da sexualidade à comida. In: Carone I, organizador. Psicanálise fim do século: ensaios críticos. São Paulo: Hacker Editores; 1998. p. 19-36.

18. Neves GN, Lazzarini ER. Os impasses da alimentação saudável e o mal-estar na atualidade. In: Viana TC, Leal I, organizadores. Sintomas alimentares, cultura, corpo e obesidade: questões clínicas e de avaliação. Lisboa: Placebo; 2013. p. 92-107.

19. Goldenberg M. Gênero e corpo na cultura brasileira. Psicol. Clin. 2005; 17(2):65-80.

20. Herrmann F. Apesar dos pesares. In: Bruno CANB, organizadora. Distúrbios alimentares: uma contribuição da psicanálise. Rio de Janeiro: Imago; 2011.

Recebido: 16/4/2016

Revisado: $12 / 7 / 2016$

Aceito: 20/7/2016 